\title{
Country-based analysis of COVID-19 publications in the first few months of the pandemic
}

\author{
Fatma Tokgöz Akyil ${ }^{1}$, Emre Saygili ${ }^{2}$, Hüseyin Arikan ${ }^{3}$, Mustafa Akyil $^{4}$, Dilek Karadogan ${ }^{5}$
}

\section{AFFILIATION}

1 Department of Chest Diseases, University of Health Sciences, Yedikule Chest Diseases and Thoracic Surgery Training and Research Hospital, Istanbul, Turkey

2 Department of Endocrinology and Metabolic Diseases, Canakkale Mehmet Akif Ersoy State Hospital, Canakkale, Turkey

3 Department of Pulmonary and Critical Care Medicine, Marmara University School of Medicine, Istanbul, Turkey

4 Department of Thoracic Surgery, University of Health Sciences, Sureyyapasa Chest Diseases and Thoracic Surgery Training and Research Hospital, Istanbul, Turkey

5 Department of Chest Diseases, Faculty of Medicine, Recep Tayyip Erdogan University, Rize, Turkey

\section{CORRESPONDENCE TO}

Dilek Karadogan. Department of Chest Diseases, Faculty of Medicine, Recep Tayyip Erdogan University, Rize, 53020, Turkey. E-mail: cakmakcidilek@yahoo.com ORCID ID: https://orcid.org/0000-00015321-3964

\section{KEYWORDS}

publication, COVID-19, academics

Received: 19 February, 2021, Revised: 7 April 2021, Accepted: 22 April 2021

\section{Dear Editor,}

Assisted by the advanced technology and trade, the novel coronavirus has swiftly diffused around the globe. In a matter of few months, by March 2020, the world was faced with a pandemic ${ }^{1}$. The fatality rates have varied within a wide band according to countries. Hospital capacities have been tested severely as SARS-CoV-2 spread at unprecedented rates, causing COVID-19 patients to need heavy hospitalization and intensive care. In almost all countries, lockdowns have led to economic and psychological problems. The urgency and global scope of the pandemic created a lacuna to be filled by national and international information sharing. Almost all scientific journals have prioritized COVID-19 and published additional issues to share the knowledge and experience on COVID-19. The need for inter-disciplinary and multidisciplinary collaboration required a prompt adaptation of academics to the crisis management.

We investigated the countries' contributions to the world literature during the first few months of the pandemic. All articles indexed in PubMed database between 30 December 2019 and 24 July 2020, in total 34203 articles, were reviewed via PubMed API (Application Programming Interface) from the website. Editorials on behalf of the journals, international consensus reports, and COVID-19 reports of international health organizations $(n=4361)$ were excluded.

The date of the very first reporting of a COVID-19 case of each country and the index of the journals publishing these studies (https://mjl.clarivate.com/search-results) have been coded. The publications have been coded according to first author's country and 32 countries producing over 100 publications were discussed in detail (Table 1).
According to PubMed queries, a total of 29842 articles have been published from 132 countries. Thirty-two countries with more than 100 published articles were defined $(n=27907)$. Of all the articles, 26\% $(n=7260)$ were published from the United States (US), 15\% from the People's Republic of China, and 10.8\% from Italy. These three countries with the most publications were followed by the United Kingdom (UK), India, France, Spain, Canada, Germany, Brazil, Iran, Australia, and Turkey. The mean interval between the first case reported in the country of publication was 178 days and the average publication rate was $120 \pm 38$ days. The overall mean author number was 5.78 with an average 3.56 institution collaborations.

The evaluation of the journal indexes demonstrated that of the 27907 articles, 21684 (78\%) were published in SCI-E journals; 2356 (8.4\%) in SSCI journals; 1805 (6.5\%) in ESCI journals; 2062 (7.4\%) were published in journals screened in other indexes. The countries with a publication rate higher than 15\% in SSCI journals were: Israel (19\%), Australia (17\%), and Canada (15\%).

The first-ten ranking of scientific documents by country in 2019 is as follows: US $(n=253165)$, China $(n=137507)$, UK $(n=72857)$, Germany $(n=56849)$, Japan $(n=45260)$, Italy $(\mathrm{n}=44632)$, Canada $(\mathrm{n}=42814)$, Australia, France and India. Turkey was at 16th place with 17947 documents on this ranking. The present study has shown that, more than one-fourth of all the scientific endeavor was sourced from the US, the country with the highest number of publications. China, the source country of the outbreak, ranked second followed by Italy, with one of the highest national excess death rates. These three countries, together, produced more 
Table 1. The features of countries with more than 100 publications on COVID-19 (according to publication occurence/frequency)

\begin{tabular}{|c|c|c|c|c|c|c|}
\hline Country & $\begin{array}{l}\text { Number of } \\
\text { articles } \\
\text { n (\%) }\end{array}$ & $\begin{array}{l}\text { Time interval } \\
\text { between the } \\
\text { first case and } \\
\text { screening } \\
\text { (days) }\end{array}$ & $\begin{array}{c}\text { SCIE or SSCIE } \\
\text { publication } \\
\text { rate } \\
\text { n (\%) }\end{array}$ & $\begin{array}{c}\text { Average } \\
\text { publication } \\
\text { rate (days } \pm \text { SD) }\end{array}$ & $\begin{array}{l}\text { Number of } \\
\text { authors } \\
\text { (mean) }\end{array}$ & $\begin{array}{l}\text { Number of } \\
\text { institutions } \\
\text { (mean) }\end{array}$ \\
\hline USA & $7260(26)$ & 185 & $6261(86)$ & $130 \pm 33$ & 5.36 & 3.53 \\
\hline China & 4197 (15) & 206 & 3465 (87) & $132 \pm 42$ & 7.95 & 3.64 \\
\hline Italy & 3019 (10.8) & 175 & 2677 (89) & $117 \pm 32$ & 6.42 & 3.56 \\
\hline UK & $2412(8.6)$ & 175 & 2133 (88) & $120 \pm 34$ & 4.56 & 3.51 \\
\hline India & $1278(4.6)$ & 175 & 968 (76) & $127 \pm 34$ & 4.25 & 3.60 \\
\hline France & $987(3.5)$ & 182 & $900(91)$ & $125 \pm 32$ & 7.00 & 3.58 \\
\hline Spain & $968(3.5)$ & 115 & $828(86)$ & $68 \pm 29$ & 5.84 & 3.37 \\
\hline Canada & $862(3.1)$ & 180 & 765 (89) & $122 \pm 35$ & 5.21 & 3.67 \\
\hline Germany & $673(2.4)$ & 179 & 584 (87) & $124 \pm 34$ & 6.17 & 3.69 \\
\hline Brazil & $670(2.4)$ & 150 & $552(82)$ & $104 \pm 31$ & 5.19 & 3.54 \\
\hline Iran & $596(2.1)$ & 156 & 467 (78) & $100 \pm 34$ & 4.79 & 3.48 \\
\hline Australia & $590(2.1)$ & 181 & 537 (91) & $127 \pm 36$ & 4.60 & 3.36 \\
\hline Turkey & 454 (1.6) & 135 & 396 (87) & $88 \pm 30$ & 4.54 & 3.50 \\
\hline Singapore & $428(1.5)$ & 135 & 297 (93) & $116 \pm 37$ & 5.99 & 3.57 \\
\hline Switzerland & $374(1.3)$ & 150 & $298(80)$ & $87 \pm 38$ & 5.19 & 3.41 \\
\hline Japan & $330(1.2)$ & 190 & $280(85)$ & $136 \pm 38$ & 6.12 & 3.46 \\
\hline Holland & $273(1)$ & 190 & 243 (89) & $96 \pm 34$ & 6.41 & 3.32 \\
\hline Korea & $265(0.9)$ & 183 & $202(76)$ & $121 \pm 41$ & 5.48 & 4.18 \\
\hline Taiwan & $244(0.9)$ & 185 & $230(94)$ & $123 \pm 36$ & 5.22 & 3.29 \\
\hline Belgium & $235(0.8)$ & 171 & 213 (91) & $118 \pm 33$ & 6.85 & 3.34 \\
\hline Pakistan & $197(0.7)$ & 120 & $158(80)$ & $74 \pm 30$ & 3.79 & 3.58 \\
\hline Greece & $196(0.7)$ & 149 & 162 (83) & $98 \pm 32$ & 5.37 & 3.71 \\
\hline Israel & $173(0.6)$ & 154 & $148(86)$ & $101 \pm 32$ & 4.87 & 4.09 \\
\hline Ireland & $171(0.6)$ & 146 & 118 (69) & $95 \pm 31$ & 4.34 & 3.65 \\
\hline Mexico & $165(0.6)$ & 146 & $126 / 76)$ & $97 \pm 31$ & 5.99 & 3.80 \\
\hline Poland & $148(0.5)$ & 142 & $127(86)$ & $97 \pm 36$ & 5.49 & 4.02 \\
\hline Portugal & $136(0.5)$ & 173 & $123(90)$ & $120 \pm 34$ & 4.27 & 3.41 \\
\hline Thailand & $130(0.5)$ & 193 & $106(82)$ & $122 \pm 39$ & 3.29 & 3.42 \\
\hline Hong Kong & $123(0.4)$ & 183 & $113(92)$ & $112 \pm 37$ & 4.63 & 3.36 \\
\hline Egypt & $122(0.4)$ & 161 & 107 (88) & $109 \pm 35$ & 4.14 & 3.57 \\
\hline Saudi Arabia & $120(0.4)$ & 144 & 98 (82) & $93 \pm 34$ & 4.58 & 3.47 \\
\hline Sweden & $110(0.4)$ & 175 & $78(71)$ & $112 \pm 175$ & 5.26 & 3.18 \\
\hline Total & 27906 & 178 & $24040(86)$ & $120 \pm 38$ & 5.78 & 3.56 \\
\hline
\end{tabular}

than half of the total global publications. When compared with all annual articles, US and China preserve the first two rows. Italy seems to share scientific research more rapidly. India and Spain have also risen to the front rows during the COVID-19 crisis. A question arises on the relationship between positive cases reported within a country and publication dates. Interestingly, the date of the first reported case does not cause a dramatic change in the ranking, showing that scientists' willingness and capacity to respond to novel scientific questions are not determined by national predicament.

An analysis of publications in high-impact journals by 
emergency physicians between 2008 and 2017 has reported the national contribution of all publications as: US 54.4\%, Canada 7.2\%, Australia 6.2\%, Turkey 4.3\%, and UK 4.1\%. Additionally, the top three countries have been the US, Canada and the UK when the scoring is examined according to the impact factor ${ }^{2}$. In endocrinology journals, the Web of Science database search between 2010 and 2014 revealed that the four most frequently publishing countries were the US (27\%), China (7\%), Italy (5.7\%), and UK (5.6\%). Turkey ranked $16 \mathrm{th}^{3}$. All these numerical findings show that the US maintains its leadership status by quickly adapting to an acute global health crisis, while Turkey remains around 13th in response capacity. The fact of being the very first country to experience the disease may have contributed to the raking of China as second behind the United States. Other than these two countries, the most frequently publishing countries did not rank in line with their national mortality rates or casepopulation ratios. In Turkey, the prevalence and fatality rate of COVID-19 was lower than other countries and the duration from the first case to publication was shorter than the sum of other countries publishing more than 100 articles. Such heterogeneity of frequently publishing countries in terms of their national case rate places a question mark over the association between national extent of this health crisis and the pace of publications.

Technical limitations did not allow automatic download of article type information as they were not available in coded form. Because manual evaluation was not feasible, we did not evaluate studies by type. However, we believe that any published work, regardless of its type is of high worth, especially during a global health crisis.

In conclusion, the ongoing health crisis did not deprive academics of their response capacity. On the contrary from the onset of the crisis, academics adapted rapidly and within seven months produced more than 30 thousand scientific publications. US, China and Italy were the most prolific scientific article publishing countries on the subject.

\section{REFERENCES}

1. Sohrabi C, Alsafi Z, O'Neill N, et al. World Health Organization declares global emergency: A review of the 2019 novel coronavirus (COVID-19). Int J Surg. 2020;76:71-76. doi:10.1016/j.ijsu.2020.02.034

2. Kokulu K, Mutlu H, Sert ET. Scientific Publication Productivity of Emergency Physicians: A Bibliometric Analysis of the Last Decade. J Emerg Med. 2019;57(1):13-20. doi:10.1016/j.jemermed.2019.03.021

3. Zhao X, Ye R, Zhao L, et al. Worldwide research productivity

\section{CONFLICTS OF INTEREST}

The authors have completed and submitted the ICMJE Form for Disclosure of Potential Conflicts of Interest and none was reported.

\section{FUNDING}

There was no source of funding for this research. in the field of endocrinology and metabolism - a bibliometric analysis. Endokrynol Pol. 2015;66(5):434-442. doi:10.5603/EP.2015.0054 